\title{
Comparative Study of Khaje Rashid al -Din Views on Rab-e Rashidi Islamic Utopia and Kevin Lynch Ideas
}

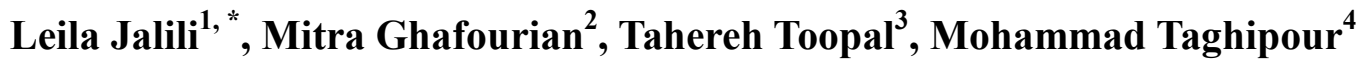 \\ ${ }^{1}$ Architecture Engineering, non-profit institution of higher education, Aba - Abyek, Qazvin, Iran \\ ${ }^{2}$ Architecture Engineering, Architectural College of Science and Technology University, Tehran, Iran \\ ${ }^{3}$ Architecture Engineering, Islamic Azad University of Shiraz, Fars, Iran \\ ${ }^{4}$ Department of Industrial Engineering, Science \& Research Branch of Islamic Azad University, Tehran, Iran
}

\section{Email address:}

mt.ghafourian@yahoo.com (M. Ghafourian), Jalilileila87@gmail.com (L. Jalili), Taherehtoopal1981@gmail.com (T. Toopal), mohamad.taghipour@srbiau.ac.ir(M. Taghipour)

\section{To cite this article:}

Leila Jalili, Mitra Ghafourian, Tahereh Toopal, Mohammad Taghipour. Comparative Study of Khaje Rashid al -Din Views on Rab-e Rashidi Islamic Utopia and Kevin Lynch Ideas. International Journal of Archaeology. Vol. 3, No. 5, 2015, pp. 39-47. doi: 10.11648/j.ija.20150305.11

\begin{abstract}
Utopia is considered to be the physical form of an ideal human society where the goals are met. Rab-e Rashidi is one of the Islamic utopia that has practically manifested and this view on ideal city in today's modern urbanization can be received based on the perspectives of Kevin Lynch (the contemporary theorist). Therefore the purpose of this study is to compare the pattern of Rab-e Rashidi and Kevin Lynch's opinions in order to determine the overlap extent of these two views. Hence those patterns that could promote the quality of Rab-e Rashidi's urban space are studied then these concepts are compared with Kevin Lynch's perspectives. The research has been done descriptively-comparatively based on library studies and written documents. The results demonstrate the social justice, attention to infrastructure, dynamics in in physical aspects of the city, mental image and climate considerations concepts which promote the quality of life in Rab-e Rashidi that compared with Lynch's views, the mentioned concepts in Rab clearly overlap with all of Lynch's views except that the concepts have been expressed more perfectly comprehensively in Rab-e Rashidi. Finally Rab-e Rashidi can be a comprehensive model of Islamic utopia for designing modern cities.
\end{abstract}

Keywords: Utopia, Khaje Rashid al-din, Rab-e Rashidi, Kevin Lynch

\section{Introduction}

During time, man has always sought to reach perfection and to achieve this he has attempted to create a suitable situation for his activities where he can grow and develop. As we see in different cultures this safe place is considered as a coherent skeleton of the city in which different groups play their roles every day and they see the city's events as capable observers and they judge. Is it truly easy to deal with this major issue? Though the city and urban design have been neglected by different groups for many years that we have witnessed irreparable damages such as grey ${ }^{1}$, insecure and confused cities with sophisticated and more confused actors. Nowadays quality crisis in cities have converted the favorable quality of urban design to one of the main centerpiece of professional associations and organizations in current situation but ambiguous and complex nature of the quality concept and diverse interpretations caused dispersion and incoherence in presented opinions. (Golkar, 2010, 88) Hence, it should be noted that the importance of the environment's physical quality and resident's quality of life are interrelated so that an urban design would be useful which is able to promote people's thought and their view towards life. Therefore, considering the necessity and importance of this in the present, on the one hand study it has been attempted to explore Kevin Lynch opinions and perspectives on favorable urban design for contemporary cities and on the other hand considering Iran's high culture and rich lands, the opinions of the educated scholar Khaje Rashid al din fad al- Allah Hamedani on Rab-e Rashidi utopia design have been observed and these two theories are comparativel studied. So one of the goals of this research is to investigate the concepts that have promoted the quality of the city and have led it to be known as one of the Islamic utopias and another goal is to explore the extent of the overlap of these elements and Lynch's contemporary view. The results demonstrate that the design principles in Rab'-e Rashidi not only conform to Lynch's described concepts but 
they also have been expressed more comprehensively, and they can be applied in contemporary design of the city.

\section{Methodology}

In this research perspectives and opinions on Rab-e Rashidi Islamic utopia and Kevin lynch -the contemporary theorist concepts on urban design have been studied using comparative-descriptive method and comparative tables. To accomplish this purpose, the collected data have been analyzed using library resources, observing the hypothetical scheme of Rab-e Rashidi and also studying its endowment letter.

$$
\text { Research Framework }
$$

\section{Utopia}

Coordinates and features of utopia have a long history. Sometimes utopia is presented as a disquisition, sometimes in a form of a protest and sometimes a scheme for life and sometimes considering the society situation, the utopia is ascertain in practice(Habib, 2010). We can see a description of an earthly paradise for the first time in the Sumerian Epic of Gilgamesh in the second millennium BC. But in the historical era especially after Islam, for the first time, an Iranian philosopher Al- Farabi, in the book Ara Ahl Al - Madina Al-Fadilah (The virtuous city), proposed ideas of an utopia that was a combination of Plato's philosophical ideas and Islam sharia(Asil, 2002, 19).Actually utopia is an ideal human society designing in which man can achieve his goals and aspirations and it includes rich concepts such as justice, equality, order and harmony, psychological comfort and etc (Habib, 2000, 209). Utopia is an earthly city where people have certain positions in that and this order is specified by law that is made by human being. Utopia is a dream to go back to the paradise that man had driven out of it but in the formation of utopia, features of this paradise are attributed to an earthly city that human life manifested in. (Shahsani, 1998, 22). Also at the conceptual level, utopia is the embodiment of an ideal city that has been man's old wish; a natural human lifelong dream. In fact, with realization of this dream a place will be found that is the society of goods and virtues. Defined features of this place are so amazing that few people would not desire to go there (Matalabi and Naderi, 2009, 130). Like Khaje Rashid Al - din Fadllah's utopia which is the physical form of one thought in place and time and it is one of the few utopias that has practically manifested in the history of urban design (Habib, 2010, 93).

\section{Rab'-e Rashidi City}

Khaje Rashid Al - din, that reached the peak of authority during Ghazan Khan government, started to build a city in north west of Tabriz (in the foot of the Sorkhab mountain) because of owning blessings and named that city Rab'-e Rashidi which is claimed to be the world's first industrial and studious city in Ilkhani era. In designing this city, Khaje Rashid Al-Din sought to run all different aspects of building a city especially scientific and religious ones in the structure and formation of the city. Hence, he provided all the needs of the city in a coherent unite from inns, shops and houses to economic units such as textile intinction and mint factories. (Balali \& Keynezhad, 2011, 138). It should be noted that in this era Islamic cities grew on the one hand by following the preceding method of urban designing and on the other hand by innovating in creation of exclusively religious buildings such as mosques, schools, shrines and monasteries (Kiani, 2000, 2) and Rab'-e Rashidi was no exception. Today none of the components of Rab'-e Rashidi is detectable and the most obvious parts are base of the towers and the lines of fortification walls [Borooshky, 1988, 65). Referring to the available evidence the establishing goals of this utopia are as follows:

- Establishing a town outside of the central core of Tabriz in order to raise the defense strength of Tabriz (passive defense).

- Constructing the world's largest campus that is formed based on the endowment religious tradition.

- Establishing a city for commercial transactions and medical and religious affair.

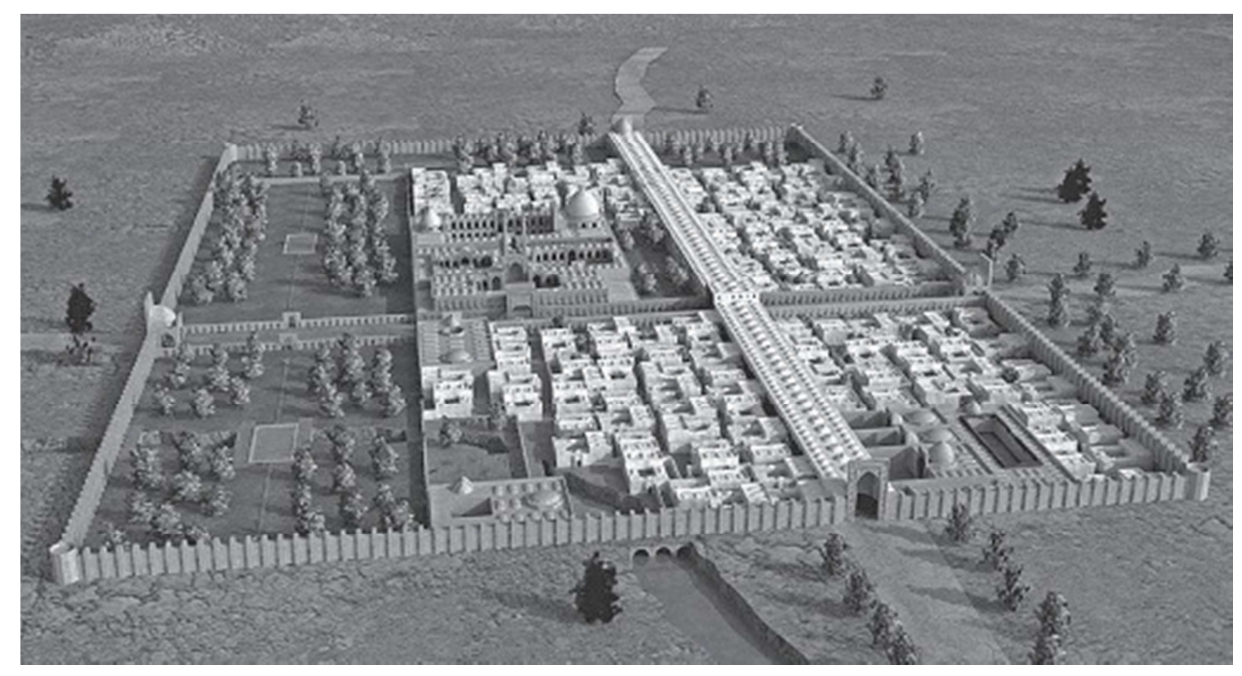

Fig. 1. Rab'-e Rashidi city (source: Balali \& Keynezhad, 2011). 
Rashid Al-din divided this into two parts. Including: 1.Central part of Rab'-e Rashidi and 2. Rashidi City (Picture No-1). This city was composed of different streets and neighborhoods in a way that every neighborhood or street was devoted to special caste or class of scholars, scientists and the intellectual companions. Popular Street and neighborhoods are scholar's alleys and student's neighborhood. Two alleys belonged to Quran reciters that each one was known and famous among city's street and alleys because of the hundreds of reciters from Kufa, Basra, Sham and etc(Kiani, 1987, 544).

\section{Concepts and Models from Rab'-e Rashidi Utopia}

By exploring the patterns in the hypothetical scheme of the Rab'-e Rashidi and it endowment letter, in this utopia four general concepts of social justice, attention to infrastructure, dynamics in the city and climate considerations, that each of these contains more detailed concepts, can be achieved.

\subsection{Social Justice}

Justice as a concept with high level of abstraction has been always kept human mind busy(Poorezzat, 2006, 85). David Harvey in his book " Social justice and the city" used social justice concept in contributing to public distributing incomes in places, equitable allocating of resources and meeting the basic needs of people (Shakoei, 1999, 14) and in Harvey's opinion, to achieve social justice, the society is required to be organized in such way that what is produced in the society can be shared in certain proportion among individuals and groups, In other words the society should turn to a targeted organization in order to realize the goals of social justice(Ghaninezhad, 1993, 45). One of the discussed concepts in Rab'-e Rashidi is social justice consideration among people that its physical aspects in the city can be seen as follow:

1. Considering the best action that is charity (endowment), and turning it to a municipal institution in built facilities in Rab'-e Rashid [Borooshki, 1998, 62) and allocating part of Rab'-e to public charities and an almshouse that committed to feed poor people every day (Blair, 1387, 63).

2. Considering social and cultural assimilation in establishing city, distinct neighborhood classification and the placement of each caste and profession in its realm which is a rational evidence to confirm this (Habib, 2010, 98).

3 . In addition to the religious and scientific core inside Rab' and the formation of the neighborhoods and residential houses, Rab'-e Rashid, had other urban spaces such as Bazar, mosque, baths, inns, Mosala, pathway, paper mill, mint and almshouse(Noghrehkar and colleagues, 2010, 53). Therefore we can say that, the allocation and equal management of the city resources, social class conflict in this city was inconspicuous and social justice was seen in the city.

\subsection{Attention to Infrastructures}

In the most general case urban infrastructure is a set of interconnected structural elements and in many cases it is construed that it includes these quality elements: access networks, water supply, sewage management, communication and a complex system (Behzadfar, 2009, 32). But a comprehensive definition of infrastructure is not only the constructive, architectural and urbanism facilities but it also covers operational procedures, methods management and extensive politics that interact with physical world (National Academy, 1987) This means that to what extent elements which are used for users and city appearance and its quality improvement can be useful in achieving the goals of urban planning and how consumption expenditures are supplied. Overall these factors are called municipal infrastructure during constructing this city, in addition to the precision in design and construction of the urban spaces, Khaje Rashid al-din paid special attention to urban infrastructure, such a way that after reading the endowment letter a brief information about water supply system, sewage system and access and performance network can be achieved.

1. water supply: There has been 3 passages (conduit) with the names; safe, middle and Acer in this city that the water of each of them has been poured in aqueduct and after that in pipes of the houses and baths. Khaje Rashid al-din described the usage condition of these water pipes on p 208 of endowment letter as follow:

- And the condition is that no one use the water of these aqueducts from the original passage and no one takes that to the houses and alleys, except the amount on top of the city that is needed for bath.

- ...What water right from this water and it goes to the drinking foundations (Saqqakhaneh) in front of Rashidi Grand mosque and from there to the pipes that are built for that drinking foundation and comes out of that places in a way that no one cannot wash anything in that and no one cannot capture it except to take a jug or a jar of water. Even it can be noted that in winters warm water was driven to the orange and bergamot trees through culvert in order not to freeze and suffer (Noghrehkar and colleagues, 2010, 62).

2. Sewage system: Rashid al-din paid special attention to keep the water of aqueducts clean therefore, he had built sewages in each neighborhood too collect the waste pollution in the city, the evidence of this system can be seen in the second chapter of endowment letter that is frequently repeated that the water waste should not be spilled in aqueduct's canal because it infects water. He also described the proper use of the urban sewage on page 211 of endowment letter as follow:

4 pipes go to a divider that is on the threshold of Rab'-e Rashidi and under miles, this water is used for consumption of houses and fountains of lower neighborhoods and also city's public baths that are located in neighborhood and a pond that is at the gate of Tabriz. The waste water goes out of the city 
and it is driven to the pathway (Balali \& Keynezhad, 2011, 60) and etc.

3. Access network: Texture of the city had geometric order and it was organized in a form checkered network. The most important element in the city was the verticality of two main axis of pathway and Bazar (Bazar is located in east-west axis and pathway is located in north south axis) that through these two axes, the access to other parts of the city was possible (Picture No.2).

4. Efficiency: All the management and urban planning's goals in Rab'-e Rashidi have been provided the community's economic infrastructure because the economic turnover of the community was supplied through various businesses such as inns, markets and factories.

\subsection{Dynamics in the City}

Urban dynamism means that the businesses and other shaping elements of the city environment should be designed in a way that encourage the sense of presence of people in the environment and through this the city becomes dynamic. In fact, city's functions have a close interaction with the city's dynamic (Habib, 2008, 9]). Faddlolah Hamedani has divided the Rab'-e Rashidi in four main parts and they are:

1. Shrine: a place with 4 porches that includes cupola (Tomb) that itself includes crypt and Dar al-Hafeiz(Noghrehkar and colleagues, 2010, 64) and Seyfi mosque (summer) which Friday and holiday's prayers were held in that. Other parts of shrine were: rooms, special rooms for teachers and students and facilities such as bath, pool house, drinking fountains and library (Habib, 2010, 96).

2. Convent: a place where the resident purify their personality and reinforce their self - esteem based on their physical power by Seir and Suluk that was Sufi's way

(Fazlollah, 1971, 42).

3- Guest house: a place for hosting guests, residents and brokers.

4- Hospital: a place to receive patients and to teach medical and get medicine.
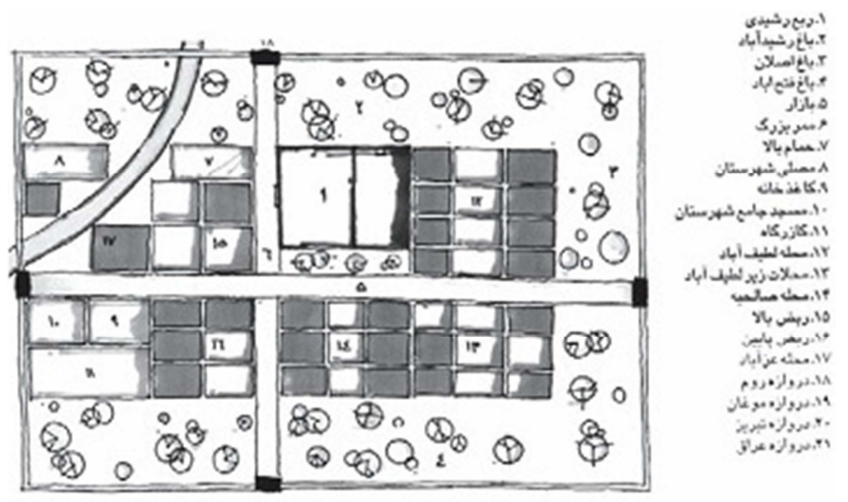

Fig. 2. Rab'-e Rashidi Plan (source: Balali \& Keynezhad, 2011).

In addition, Rashid Al-Adin did not underestimate building Bazars, factories and inns among with, religious goals (designing Rab'-e Rashidi), cultural goals (building medical school) and social goals (paying attention to the endowment tradition and its social functions like building almshouse). That this important factor resulted in dynamics in the city. (Picture No. 2). Hence, it worth saying that urban spaces constitutive elements and their functions encouraged people to be present in the environment and city privileged dynamism.

\subsection{Climate Considerations}

Table 1. Review of the concepts in different areas of Rab'-e Rashidi (Source: Authors).

\begin{tabular}{|c|c|c|}
\hline concepts & City Area & Concepts place in the city \\
\hline \multirow{3}{*}{ Social Justice } & private & $\begin{array}{l}\text { Depending on the profession of the head of the family, the house has been located in the special neighborhood } \\
\text { of that social layer }\end{array}$ \\
\hline & \multirow{2}{*}{ public } & Including homogeneous social group \\
\hline & & Defined cultural-zones \\
\hline \multirow{4}{*}{ Attention to infrastructure } & \multirow{4}{*}{ private } & Formation of city cores in a form of neighborhoods \\
\hline & & Impact on the spatial hierarchy and formation of the areas \\
\hline & & Plumbing system and household water supply \\
\hline & & Waterway, sewage and access networks \\
\hline \multirow{5}{*}{ Dynamics in the city } & \multirow{3}{*}{ private } & Separation of the public and private area \\
\hline & & Formation of spatial hierarchy \\
\hline & & Public groups activities in one context \\
\hline & \multirow[b]{3}{*}{ private } & Separation of neighborhood areas- Designation of family privacy \\
\hline & & Neighborhoods name compatibility with social layers \\
\hline Climate Consideration & & Introverted and unity oriented architecture with observance of the space access hierarchy \\
\hline
\end{tabular}

One of the important element of the environment is climate and its related issues. Hence, climate consideration in designing is one of the important priorities in urban design(Hoseini, 2013, 45). Climate consideration means to create suitable natural environment for consumers among having harmony with the environment and deriving benefit from it within its natural forces(Kasmaee, 2000, 8). Rab'-e
Rashidi architecture and urbanism had its own ways to create harmony with nature and to decrease consumption and use natural forces; because he paid special attention to the natural potential of the area like irrigating eastern arid lands and agricultural development in that places, shallow resources, water and soil features and irrigation circumstances (Saber, $2011,46)$ and by east - west orientation towards Tabriz, with 
applying the deviation angle of Qiblah in addition to the benefits from the predominant wind (Northeast) that subtilized air, cluster path of the aqueducts were shaped in accordance with the natural substrate and with this flexible design it became closer to its goal which is constancy in the construction of the city (Nikpour, 2008, 16) He also paid special attention to the compatible architecture with climate in designing the city's buildings, in a way that introverted, unity orientated and centralized architecture that consists of different areas with spatial hierarchy from public to completely private (separated areas included entrance, porch, patio, room, hall, shahneshin, services and spaces, basement, cellar and water storage) (Habib, 2010, 99) Table one has described all the concerns derived from Rab'-e Rashidi utopia in two public and private areas and has introduced manifestation for each concept.

After studying and clarifying the goals of Rab'-e Rashidi utopia, Kevin Lynch's opinions and viewpoints are studied.

\section{Kevin Lynch's Urban Design Patterns}

From the Lynch's view, city is not only a factor that is observed by millions of people from each class, but also it's the product of manufactures that change its building depending on the society's needs while the general appearance of the city remains constant for a while. Lynch knew the city's appearance as a connected setting that if one of the factor's changes, the other factor will change, sequence of elements with the same melody that can be responsive to its contrasting melody and all of the elements of the city's appearance influence on the viewer and create an image in his mind (Lynch, 1993, 66). This means that one must have a clear picture of the environment in which he is and this leads to create an effective and useful foundation in the development of his mental faculties, in other words, when the scene is clear, precise and vivid, he takes a social role and this good image of the environment gives a sense of security to the person and increase the human experience of the environment.

\subsection{The Forming Elements of a Favorable Urban Appearance}

According to Lynch's view in order to create a favorable urban environment, there are elements that can affect directly on the appearance of the city and indirectly on the mental image of its inhabitants. These elements are:

1. Way: that might be roads, streets, sidewalks underground lines, trams, railways and etc. It is the path that actual or potential movement is done through it (Lynch, 2011, 90).

2. Edge: is a linear factor which varies with the way from the view of the observer. Edges are side factors and not balance and symmetry axis. Sometimes they block other factors and sometimes they make connection between two factors (Lynch, 2011, 91).

3. Knot: knots are critical areas in the city that are made because of the presence of neighborhoods and roads and the observer enters them. Sometimes knots are caused by the crossing roads and sometimes they are the core of a
neighborhood(Lynch, 2011, 92).

4. Sign: Signs are the factors in determining different parts of the city and they are considered as a factor to identify and navigate an environment. Sometimes signs are on large and urban scale and sometimes on regional scale (Lynch, 2011, 93).

5. Neighborhood: neighborhoods are parts of the city that are either on medium or large extent. Elements of each neighborhood are recognizable because of having common characteristics but the appearance of the neighborhood can be distinguished from the inside of them and if they are visible from outside, the can be used for finding various points(Lynch, 2011, 91).

Any of these factors cannot be studied alone and each factor covers other factors and penetrates in them. It can be said that neighborhoods have connections with knots, edges specify their extent and we can enter them through ways and finally signs differentiate their appearance. (Habib, 2006, 8). In this process, the person regularizes the received from the environment and in addition to the components, he portrays the existing order between them in his mind and gives it meaning. Hence, a city will have a favorable appearance in which all the mentioned points are being observed in in it.

\subsection{Effective Concepts on the Improvement of Urban Design Quality}

Lynch has always emphasized on the interrelation and the effects of the urban design quality on the residents quality of life. To have a useful urban design, it should be able to improve human's life quality through improving the quality of the physical environment, said Kevin Lynch (Golkar, 2006, 43) Concepts that influence on improving the urban design in Lynch's view are:

1. Vitality: is the possibility of human cognitive and biological survival in the city's environment. This means how the form of the city makes the continuity of vital functions and satisfaction of human biological needs possible (Lynch, 2011, 96).

2. Meaning: is mental role motivation and significance of urban places that provides the possibility of environment's adaption to human's emotional and mental ability and cultural structure(Golkar, 2011, 96).

3. Congruence(compatibility): means the adaption of city's form, capacity and the size of physical spaces to the man's present and future activities.

4. Access: access means the ease of physical penetrations o the various parts of the city in an optimal level(Golkar, 2011, 98).

5. Supervision and authority: means to provide the choice possibility and intervention of the citizens in public areas and people's active encounters with spaces in the city(Golkar, 2000, 42).

Hence, it can be said that Lynch believed that a good city meets the biological and cultural needs of its inhabitants and a good place adapts with the person and his cultural background and informs him about the place where he is in(Golkar, 2011, 98). 


\section{The Comparison of Khaje Rashid and Kevin Lynch Ideas}

According to the provided information, the physical design of a city should reach a degree that not only meets the needs of its time but it also can be used as a helpful model. The necessity of this important issue has helped the authors to classify the obtained data in table 2 and explore the extent of overlap of two theories in order to determine whether the utopia which had designed 8 centuries before the Lynch's idea can cover the favorable urban design concept in the contemporary era and be responsive to today's needs or not.

Table 2. Comparison and adaption of concepts from Rab'-e Rashidi and Kevin Lynch's Theory (Source: Authors).

\begin{tabular}{|c|c|c|c|c|}
\hline \multicolumn{3}{|c|}{ Features of Khaje Rashid al-Din Utopia } & \multicolumn{2}{|c|}{ Features of Kevin Lynch Utopia } \\
\hline \multirow[t]{4}{*}{ Concepts } & & Analysis & Concepts & Analysis \\
\hline & & $\begin{array}{l}\text { Considering charity (endowment) and turning it to a } \\
\text { municipal institute }\end{array}$ & & \\
\hline & Equality & $\begin{array}{l}\text { Considering the social and cultural standardization in } \\
\text { neighborhood classifications in the city }\end{array}$ & & - \\
\hline & & Allocating a part of city to public charity & & \\
\hline \multirow[t]{5}{*}{$\begin{array}{l}\text { Social Justice } \\
\text { Social Justice }\end{array}$} & $\begin{array}{l}\text { Supervision } \\
\text { and Authority }\end{array}$ & $\begin{array}{l}\text { Considering various construction and fair division of these } \\
\text { space } \\
\text { Existence of the choice possibility to participate in different } \\
\text { areas for residents }\end{array}$ & $\begin{array}{l}\text { Supervision } \\
\text { and Authority }\end{array}$ & $\begin{array}{l}\text { Providing the possibility of choice and } \\
\text { intervention for residents in various areas } \\
\text { of the city }\end{array}$ \\
\hline & Function & Formation of the diverse functions in Rab' including: & Function & $\begin{array}{l}\text { Accommodating various activities with } \\
\text { form of the city }\end{array}$ \\
\hline & Congruence & religious, environmental, economic and etc. & Congruence & $\begin{array}{l}\text { Accountability to the resident's } \\
\text { environmental and cultural needs }\end{array}$ \\
\hline & Access & $\begin{array}{l}\text { Benefiting from checkered design network and creating a } \\
\text { regular contexture }\end{array}$ & Access & $\begin{array}{l}\text { Ease of physical penetration in different } \\
\text { part of the city }\end{array}$ \\
\hline & Water Supply & $\begin{array}{l}\text { Transferring aqueduct water to the baths and houses } \\
\text { thorough pipes }\end{array}$ & - & - \\
\hline \multirow{3}{*}{ Infrastructures } & & Benefiting from warm water in winters for trees & & \\
\hline & Sewage & Providing sewage to collect pollution in the city & - & - \\
\hline & Efficiency & $\begin{array}{l}\text { Providing financial circulation through inns, bazars, } \\
\text { factories }\end{array}$ & - & - \\
\hline \multirow{6}{*}{$\begin{array}{l}\text { Dynamics in } \\
\text { the city }\end{array}$} & & & & $\begin{array}{l}\text { Biological and comprehensive survival in } \\
\text { the city }\end{array}$ \\
\hline & Vitality & cultural, educational, economical and etc. & Vitality & $\begin{array}{l}\text { Encouraging people's sense of presence } \\
\text { thorough creating various elements and } \\
\text { uses }\end{array}$ \\
\hline & Meaning & $\begin{array}{l}\text { Using endowment's ideas and concepts in a municipal } \\
\text { institution with social functions in creating urban spaces and } \\
\text { forming its elements and their continuity and management }\end{array}$ & Meaning & $\begin{array}{l}\text { Mental role encouraging and the } \\
\text { significance of the urban places that } \\
\text { transfer a specific signal }\end{array}$ \\
\hline & & Bastions and ramparts around the city & & Inferior elements that sometimes block \\
\hline & Edge & West side city's river & Edge & other elements and sometimes connect \\
\hline & & Neighborhoods separator edges & & other elements. \\
\hline \multirow[t]{4}{*}{ Mental Image } & Knot & $\begin{array}{l}\text { The intersection of two defining axes of bazar and pathway } \\
\text { in the center of the city } \\
\text { Mofateh al-abvab knot in the city }\end{array}$ & Knot & $\begin{array}{l}\text { Critical areas that are made because of the } \\
\text { presence of neighborhoods and roads and } \\
\text { observer enters them. }\end{array}$ \\
\hline & Sign & $\begin{array}{l}\text { Dome house as the focal point of the city } \\
\text { Four main gates in four directions }\end{array}$ & Sign & $\begin{array}{l}\text { An element for navigation and better } \\
\text { identification of an environment and } \\
\text { recognizing the different parts of a city }\end{array}$ \\
\hline & Neighborhood & $\begin{array}{l}\text { Allocating each neighborhood to one class or one profession } \\
\text { that is eligible for center } \\
\text { Compatibility of neighborhood's names with social strata }\end{array}$ & Neighborhood & $\begin{array}{l}\text { Parts of the city that are either medium or } \\
\text { large and should have two dimensions } \\
\text { that the observer feels that he enters it }\end{array}$ \\
\hline & Orientation & $\begin{array}{l}\text { Observing the climate considerations in the city with proper } \\
\text { orientation } \\
\text { Benefiting from the natural potentials of the region like } \\
\text { agricultural development }\end{array}$ & - & - \\
\hline \multirow[t]{2}{*}{$\begin{array}{l}\text { Climate } \\
\text { Consideration }\end{array}$} & & $\begin{array}{l}\text { Considering climatic architecture as introverted and focused } \\
\text { architecture }\end{array}$ & & \\
\hline & Architecture & $\begin{array}{l}\text { Considering the spatial hierarchy in various areas from } \\
\text { private to fully public and benefiting from the local materials } \\
\text { in constructing buildings }\end{array}$ & - & - \\
\hline
\end{tabular}




\section{Discussion}

According to the table 3 in Kevin Lynch idea it is clear that, it has been attempted to pay attention to all the needs of human being in designing a favorable city, but by comparing it to Khaje Rashid al-Din ideas and evaluating the overlap, it is determined that the attention to this concept in Rab'-e Rashidi has provided on a wider scale.

- Addressing the concept of dynamics in the city, that has been seen with more detailed concepts like vitality and meaning, has the highest overlap. As a full explanation has been provided for this concept in Kevin Lynch idea, likewise Khaje Rashid al-Din paid special attention to the dynamics in the city.

- Mental image concept, that has been seen with partial concepts like way, edge, knot, sign and neighborhood, has been surveyed comprehensively in both views. Therefore, this concept has the highest overlap (100\%)
- Addressing the concept of social justice has been seen with equality, supervision and authority, congruence and compatibility concepts. In Lynch's idea this concept has been seen with partial concepts like supervision and authority, congruence and compatibility. Hence, the extent of overlap is $3 / 2(66 \%)$.

- Attention to infrastructures, that includes access, efficiency, water supply, and sewage system, was discussed only in access concept in Lynch's view. However in Rab'-e Rashidi in addition to the mentioned concept, a special attention has been paid to other concepts like efficiency and sewage system. Hence the overlap is $1 / 4(25 \%)$ and it's minor.

- Also the concept of climate considerations, that includes orientation and climate compatible architecture, has not been investigated in any of the Lynch's viewpoints on the favorable urban design. But Khaje Rashid al-Din paid special attention to this concept in designing each of the Rab'-e Rashidi spaces. So this means that, this concept has no overlap in viewpoints of Khaje Rashid and Kevin Lynch.

Table 3. Review of the extent of overlap in two viewpoints (Source: Authors).

\begin{tabular}{|c|c|c|c|c|c|}
\hline \multirow{17}{*}{ Utopia } & concept & & Rabe e Rashidi & Kevin Lynch & Overlab Extent \\
\hline & & Equality & & & \\
\hline & Social justice & Supervision and authority & & & \\
\hline & & Congruence and compatibility & & & \\
\hline & & Way & & & \\
\hline & & Edge & & & \\
\hline & Mental image & Knot & & & \\
\hline & & Sign & & & \\
\hline & & Neighborhood & & & \\
\hline & & Vitality & & & \\
\hline & & Meaning & & & \\
\hline & & Efficiency & & & \\
\hline & 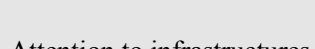 & Access & & & \\
\hline & & Water supply system & & & \\
\hline & & Sewage system & & & \\
\hline & Climate & orientation & & & \\
\hline & considerations & Native architecture & & & \\
\hline
\end{tabular}

Note: each of the graphic symbols that is used in this table means:

Complete overlap in two viewpoints

$2 / 3$ overlap in two viewpoints

$1 / 4$ overlap in two view points

No overlap in two view points

\section{Conclusion}

According to the comparative diagram of Khaje Rashid al-Din and Kevin Lynch's viewpoints (Fig.3), in Lynch idea it was attempted to meet all human needs in urban designing, eventually this will lead to design favorable cities. But in Khaje Rashid's view, there is a more comprehensive definition of human needs because of dealing with several issues like climate considerations, attention to infrastructures like sewage system, water supply, the efficiency and quality concepts that 
the attention to these needs will lead to improve the quality of environment and thus improve the quality of the city life in Rab'-e Rashidi and the formation of the a stable utopia in $8^{\text {th }}$ century. Hence, this strong ideology of the mentioned utopia can be expanded to the contemporary thought and we can derive benefit from it in today's design to reach an Islamic

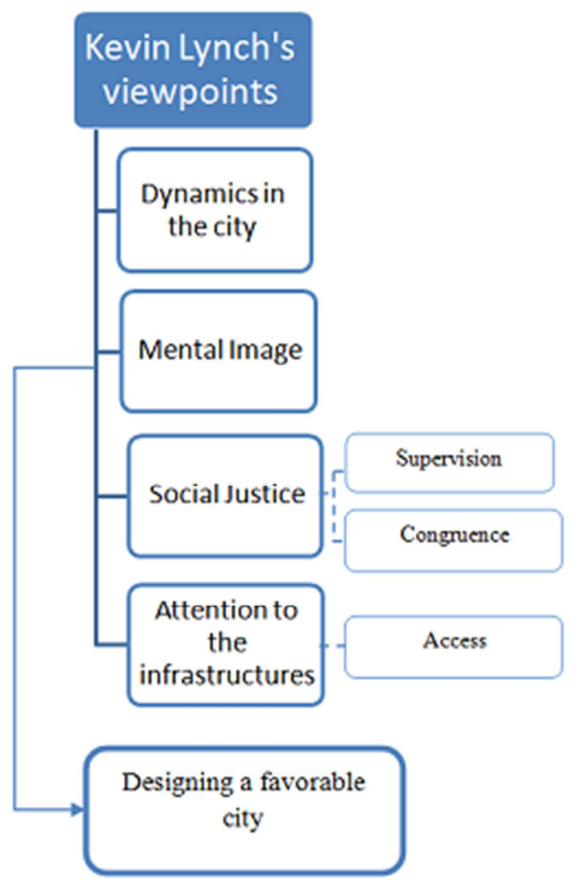

utopia. It should be mentioned that, although this pattern is suitable for cities with Islamic culture and religion, the profound concepts in urban planning, urban management, fair allocation of resources, proper orientation, attention to infrastructures like water supply and landfill system can be extended to other countries of the world.

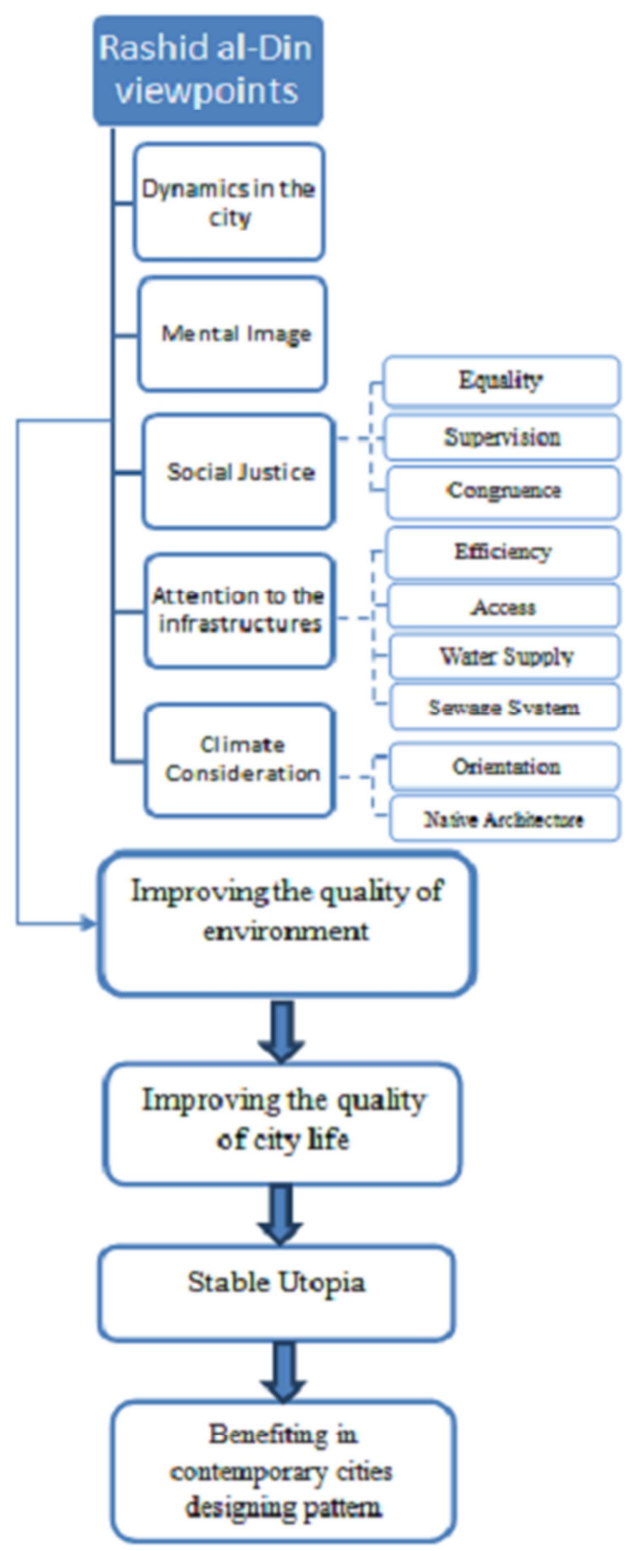

Fig. 3. The comparative diagram of Khaje Rashid al-Din and Kevin Lynch's viewpoints.

Notes: 1- According to page 169 of book "The Creation of the stable place" by Korosh Golkar: urban landscape plays an important role in people's mental image of city color through its color palette that is whether monochrome or polychrome. In fact, the reason why some cities create depressed mental image and some cities create a happy mental image is largely related to the color palette of the urban landscape. Therefore, authors decided to use grey cities because current Iranian cities do not have any colors.

\section{References}

[1] Asil, Hojjatallah. 2002. Utopia in Iranian Thought. Tehran: Ney Publications.

[2] Balali Oskuei, Azita, and Muhammad Ali Keynezhad. 2011.
Reinvented Rab-e Rashidi According to historical texts. Tehran: Institute of the Arts Publishing.

[3] BehzadFar, Mustafa. 2009. Urban infrastructure (Volume1: water supply and Sewage system). Tehran: Simaye Danesh ublications.Blair, Sheila. 2008. Ilkhan Architecture and Society, Analysis of Rab-e Rashidi Vaqf-nameh. Translated by Mehrdad Qayyumi. Golestan Art (13): 48-73. 
[4] Borooshki, Mohammad Mehdi. 1988. investigating Administrative and teaching methods of Rab-e Rashidi. Mashhad: Razavi Publication.

[5] Fazlullah Hamedani, Rashid al-Din. 1971. Rab-e Rashidi Vaqf-nameh. Efforts of Mojtaba Minavi and Iraj Afshar. Tehran: National Monument Publications.

[6] Ghani Nezhad, Musa. 1993. Justice, Social justice and economic. Baztab Andisheh Journal (15): 41-58.

[7] Golkar, Korush. 2000. Component manufacturer quality of urban design. Soffeh Journal (32): 38-65.

[8] Golkar, Korush. 2011. Creating sustainable places (A reflection on urban design theory). Tehran: Shahid Beheshti University Publications Center.

[9] Golkar, Korush. 2006. The concept of the urban landscape. Abadi Journal (53): 38-47.

[10] Habib, Farah. 2010. An analysis of urban areas in the Azeri Style (Case Study: Rashid al-Din Fazlullah Utopia - Rab-e Rashidi). Journal of Fine Arts - Architecture (41): 91-100.

[11] Habib, Farah. 2008. Morphology Urban Course notes. Tehran: Faculty of Arts and Architecture, Science and Research Branch, Islamic Azad University.

[12] Habib, Farah. 2000. Study utopia concept and its role in the development of urban. PHD Thesis. Tehran: Faculty of Arts and Architecture, Science and Research Branch, Islamic Azad University.

[13] Habib, Farah. 2006. Curiosity Within the meaning of the City. Fine Art Journal (25): 6-18.

[14] Hosseini, Seyyed Ebrahim. 2013. Thermal comfort and the impact of high buildings in urban spaces Microclimate (Case Study: Shahrdari Street of Tehran, between Tajrish Square and Ghods Square). Amayesh Mohit Journal (11): 41-56.

[15] Kaden, Jame L. 2000. Cultural literature and criticism. Translated by Kazem Firoozmand. Tehran: Shadegan Pablication.

[16] Kasmaee, Morteza, and Mohammad Ahmadi Nezhad. 2000. Climate and Architecture. Esfahan: Khak Publications.

[17] Kevin, Lynch. 1993. Good City Form. Translated by Seyyed Hossein Bahreini. Tehran: Tehran University Publishing.
[18] Kevin, Lynch. 2011. The Image of the City. Translated by Seyyed Hossein Bahreini. Tehran: Tehran University Publishing.

[19] Kiani, Mohammad Yousef. 1987. Iranian Cities(Volume 2). Tehran: Ministry of Culture and Islamic Guidance Publications.

[20] Kiani, Mohammad Yousef. 2000. Iranian Architecture of Islamic Period. Tehran: Samt Publications.

[21] Lynch, Kevin, and Michael Worth. 2009. Wasting Away. Translated by Seyyed Hossein Bahreini. Tehran: Tehran University Publishing.

[22] Lynch, Kevin, 2011. The Image of the city. Translated by Seyyed Hossein Bahreini. Tehran: Tehran University Publishing.

[23] Lynch, Kevin, 1993. The good city form. Translated by Seyyed Hossein Bahreini. Tehran: Tehran University Publishing.

[24] Matlabi, Masoud, and Mohammad Mehdi Naderi. 2009. A comparative study of the concept of utopia in Political Islam, Iran and the West. Political Studies Publication 2(6): 125-146.

[25] National Academy News. 1987. Infrastructure for the twenty-first century. United State: Washington D.C.

[26] Nikpour, Samineh. 2008. Comparative study of the morphology context of its formation and The hypothetical of Rab-e Rashidi. Thinking Architecture Journal (23): 15-23.

[27] Noghreh kar, Abdolhamid, mohammad Ali Keynezhad, and Azita Balali Oskouie. 2010. The hypothetical of "Rab" and "city" of Rashidi. Soffeh Journal (50): 49-76.

[28] Poorezzat, Ali Asghar. 2006. The Need to develop Cultural justice to achieve a Promised justice society. Tadbir Monthly Journal (167): 79-91.

[29] Saber, Mohammad Bagher. 2012. Reflective on Constructive vote of Rashid Aldin Fazlollah Hamedani (Case Study: Reading out of Initial development of fathabad Village in Tabriz). House \& Village Journal (140): 39-50.

[30] Shah Sani, Shahrzad. 1998. Nizami Ganjavi Utopia. Keyhan Farhangi Journal (148): 31- 34

[31] Shakoei, Hossein. 1999. New ideas in philosophy, geography (3 ed.). Tehran: Gytashnasy press. 